\title{
Doing more tests: Next challenge for Covid 19 in India
}

\author{
Manas Pratim Roy ${ }^{1}$ (C)
}

Received: 24 April 2020/Accepted: 24 May 2020/Published online: 1 July 2020

(C) Indian Virological Society 2020

\begin{abstract}
In response to Coronavirus 19 pandemic, countries are struggling to contain its spread and save precious human lives. Like others, India is also trying to enhance testing capacity to identify every case and break the chain of transmission. Due to several constrains like geographic distribution of the laboratories, social stigma, prevailing lockdown, people are not being able to seek medical help every time they need. In addition, the states are not doing laboratory tests in similar frequency. In future, doing extensive tests would emerge as a major strategy for stopping the progression of the pandemic.
\end{abstract}

Since the end of 2019, mankind has witnessed rapid unfolding of a pandemic, caused due to Coronavirus 19 (Covid 19). India, like other countries, is also facing the wrath of Covid 19 pandemic. By end of May, 2020, there have been 6.3 million cases globally, with 374,000 deaths. In response, the countries took unprecedented steps like closure of international borders, lock down and enforcement of social distancing. The basic aim was to prevent breakdown of fragile health system that is unable to counter such a viral onslaught. With reports that the virus is transmitting within community in US and Europe much before official recognition of such event raises the same question for India [7]. With early closure of boundaries and nation-wide lockdown, the epidemic is apparently having a sluggish growth in the country. It is supported by the fact that the number of total cases now takes more than 15 days for getting double [9].

Manas Pratim Roy

manas_proy@yahoo.co.in

1 Ministry of Health and Family Welfare, New Delhi, India
WHO, as a strategy to overcome the pandemic, suggested for extensive testing [10]. India, though following the path, is lagging much behind the European countries. For example, Italy is doing 64,664 tests/million population whereas India is doing 2876 tests/million [1].

It may be noted that Italy is also experiencing national lockdown across the country since 9th March, 2020. However, it is only extensive testing that helped to identify more than 233,000 cases till 1st June, 2020 [1]. Had India adopted similar rate of testing, by now, 88 million tests would have done which is in sharp contrast to the present figure of 3.97 million [4].

In a resource-poor country like India, detection of all cases might not be possible. As of now, there are 681 labs testing for Covid 19 [5]. At times, the testing labs are $200 \mathrm{~km}$ away from certain geographic points. With existing lockdown, how many symptomatic individuals would travel $200 \mathrm{~km}$ is a matter of further research. Only the serious cases, which constitute $20 \%$ of the total infected persons, would attempt to avail such diagnostic services, with no assurance for success. Add stigma and difficulty to arrange even the last rites of Covid 19 patients being reported to this consideration and the number of cases seeking medical help would go down drastically.

The differences between states are supporting this fact. From Table 1, it might be noted that all states with higher mortality rates are doing lesser tests. When we compare them with the states doing highest number of tests per million like Delhi, Tamil Nadu and Jammu \& Kashmir, the difference gets evident (Table 2) [States with no mortality like Goa, Tripura were not considered].

While Goa is doing 12,656 tests per million, Bihar is performing only 653 tests per million [2]. The wide difference between the states, as evident from the fact that Delhi is doing 8 times more tests per million than Uttar 
Table 1 States with high mortality rate from Covid 19 in India

\begin{tabular}{lll}
\hline State & Death rate $(\%)$ & Test/million \\
\hline Gujarat & 6.17 & 3183 \\
West Bengal & 5.63 & 2200 \\
Madhya Pradesh & 4.32 & 2092 \\
Maharasthra & 3.37 & 3867 \\
Telengana & 3.15 & 628
\end{tabular}

Table 2 States with high testing rate for Covid 19 in India

\begin{tabular}{lrl}
\hline State & Test/million & Death rate $(\%)$ \\
\hline Jammu \& Kashmir & 13,354 & 1.19 \\
Delhi & 10,979 & 2.51 \\
Andhra Pradesh & 7340 & 1.74 \\
Tamil Nadu & 6650 & 0.80 \\
\hline
\end{tabular}

Pradesh, might play a crucial role in determining further direction of the pandemic in different parts of the country. Doing enough tests brings down the mortality rate, as evident from Tamil Nadu recording $0.8 \%$ death but Gujarat putting $6.17 \%$ death on record [2].

Expanding the scope of testing may be a direct consequence of liberal testing criteria. Such a strategy would lead to inclusion of more mild cases than that of serious cases/deaths and finally result in a reduction of mortality rate. However, this should be weighed against the economic costs involved with procurement of kits, sample collection, transport and testing, apart from deployment of trained manpower at the designated centres. As lockdowns and physical distancing measures are eased, to avoid another surge of epidemic, proactive surveillance, case detection, and contact tracing with isolation will be required [8].

In fact, earlier the strategy adopted in India was to test symptomatic individuals with international travel history, contacts of positive cases, front line health workers and patients with Severe Acute Respiratory Illness [6]. Later, all hospitalised patients who develop influenza-like illness, migrants with symptoms, and symptomatic frontline workers involved in containment and mitigation were included. Even asymptomatic direct and high-risk contacts of confirmed cases were included in the expanded scope [3].

It is clear that with limited resources, extensive testing may not turn into reality in every corner of the country. With ongoing efforts for developing cost-effective test with high sensitivity across the world, there is need for linking epidemiological data with frequency of testing. As we are limping forward to a 'new normal' world, we are looking for further strengthening of laboratory services to extend the scope of diagnosis even to the remotest parts of the country.

\section{References}

1. Covid 19 Coronavirus pandemic. https://www.worldometers.info/ coronavirus. Accessed 2 June 2020

2. Covid 19 India. https://www.covid19india.org/. Accessed on 2 June 2020.

3. Indian Council of Medical Research. Strategy for COVID19 testing in India. https://www.icmr.gov.in/pdf/covid/strategy/Test ing_Strategy_v5_18052020.pdf. Accessed 2 June 2020.

4. Indian Council of Medical Research. https://www.icmr.gov.in/. Accessed 2 June 2020.

5. Indian Council of Medical Research. https://www.icmr.gov.in/ pdf/covid/labs/COVID_Testing_Labs_01062020.pdf. Accessed 2nd June 2020.

6. Indian Council of Medical Research. Strategy for COVID19 testing in India. https://www.icmr.gov.in/pdf/covid/strategy/Strat egy_COVID19_testing_India.pdf. Accessed 2 June 2020

7. Mallapty S. Antibody tests suggest that coronavirus infections vastly exceed official counts. Nature. 2020. https://doi.org/10. 1038/d41586-020-01095-0.

8. Mehtar S, Preiser W, Lakhe NA, et al. Limiting the spread of COVID-19 in Africa: one size mitigation strategies do not fit all countries. Lancet Glob Health. 2020. https://doi.org/10.1016/ S2214-109X(20)30212-6.

9. Ministry of Health and Family Welfare. Updates on COVID-19. https://pib.gov.in/PressReleasePage.aspx?PRID=1627908. Accessed 2 June 2020.

10. World Health Organization. WHO Director-General's opening remarks at the media briefing on COVID-19; 2020. https://www. who.int/dg/speeches/detail/who-director-general-s-opening-remarksat-themedia-briefing-on-covid-19-22-april-2020. Accessed 23 April 2020.

Publisher's Note Springer Nature remains neutral with regard to jurisdictional claims in published maps and institutional affiliations. 